\title{
Experimental and Numerical Optimization of Magnetic Adhesion Force for Wall Climbing Robot Applications
}

\author{
Anwar Sahbel and Ayman Abbas \\ Mechanical Engineering Department, the British University in Egypt, Cairo, Egypt \\ Email: anwar.magdy@bue.edu.eg, aabbas@bue.edu.eg \\ Tariq Sattar \\ Robotics and NDT Research Centre, London South Bank University, London, UK \\ Email: sattartp@1sbu.ac.uk
}

\begin{abstract}
Wall climbing robots require adhesion methods which are suited to the climbing surface material and roughness. In this paper, an optimum design of a magnetic adhesion mechanism has been developed for ferrous surfaces that maximises the magnetic adhesion force. This in turn maximises the payload that can be carried by the climbing robot. Experiments have been designed using the Response Surface Methodology (RSM) to study the effect of identified independent parameters (namely the distance between magnets, air gap and yoke thickness) that affect the response variable i.e. the magnetic adhesion force. A quadratic regression model has been developed to represent an empirical relationship between the response variable and the independent variables. Statistical analysis of the predicted model has been investigated using analysis of variance (ANOVA). To inspect the adequacy of the predicted quadratic model, validating experiments have been carried out at different conditions where the experimental results showed similar response values to the predicted model responses. Numerical optimisation has been applied to predict the optimum variable conditions for maximum adhesion force and air gap, resulting in an adhesion force of $240.3 \mathrm{~N}$ at $20 \mathrm{~mm}$ distance between magnets, $18.5 \mathrm{~mm}$ air gap and $8.3 \mathrm{~mm}$ yoke thickness. The optimum conditions have been numerically validated using a commercial finite element simulator. The numerically optimised design parameters have been used to design and construct a prototype wall climbing robot.
\end{abstract}

Index Terms - adhesion force, numerical simulation, climbing robot, response surface methodology, optimisation, permanent magnet adhesion system

\section{INTRODUCTION}

The adhesion force for a wall climbing robot is determined according to the material and roughness of the surface and the robot weight plus its payload. The adhesion principle is classified into five main types pneumatic [1], mechanical [2], electrostatic [3], chemical [4] and magnetic [5].

Pneumatic adhesion is the most widely used technique for wall climbing robots [6]. It is divided into two main

Manuscript received May 10, 2018; revised December 20, 2018. types - suction cups or negative pressure thrust using a vortex. The suction cups are classified as active or passive.

Passive suction cups do not use an energy supply to attach to the surface. In [7] a legged wall climbing robot is developed using passive suction cups. The robot consists of six legs each leg is equipped with a suction cup to connect to a four bar mechanism that attaches and detaches the cups from the wall. The robot motion is too slow as it uses legs for locomotion and it cannot climb rough surfaces because the suction cups work only on smooth surfaces. Since the suction cups are widely used, a lot of research has been carried out to study their adhesion force [8]. The advantage of a passive suction cup is that it has a strong adhesion force and does not require an energy supply or actuators to stick it to the surface. However, it works only on smooth surfaces and it can easily come off if the lip of the cup becomes detached. Active suction cups on the other hand require a valve and a vacuum pump for attachment and detachment. A multi-track robot was developed in [9] that can climb any wall regardless of the material composition of the surface. It has the ability to transition between surface planes while carrying a high payload. The robot is composed of five modules in the form of three parts connected with two links. Each module is equipped with caterpillar tracks with six suction cups. As a result, its design and control are very complex. Another robot uses suction cups and two orthogonal shafts with the motion of sliding frames [10].

Mechanical adhesion methods use clamping mechanisms or claws for gripping. These methods are mainly utilized on surfaces which are rough, so that the robot can find points for attachment [11]. This type of robot can stay in its place for a long time without energy supply and with a low probability of falling. However, their motion is slow, and they cannot carry a high payload or climb smooth surfaces. Other adhesion methods are based on the electrostatic force between the climbing surface (which acts as the substrate material) and electroadhesive pads that consist of conductive electrodes [12]. 
These robots can climb any wall regardless of the material of the wall. However, they have limited ability to cross obstacles and cannot carry a heavy payload.

Chemical adhesion principle has been used with different locomotion techniques for wall climbing robots. This adhesion principle can be used with any surface however the adhesion is affected by the environmental factors such as temperature, moisture and dust [4].

Many safety critical structures in industry are constructed from ferrous materials. Permanent magnet adhesion systems offer advantages of zero power requirements, high payload carrying ability and safe adhesion in the event of power failure. A permanent magnet adhesion system has been designed for a wheeled wall climbing robot carrying a laser cutting head to cut steel plates [13]. The robot was required to carry the laser head which weighs about $18 \mathrm{~kg}$ in addition to the robot weight. Accordingly, five adhesion system configurations of neodymium N42 magnet have been considered to find the maximum adhesion force. Each magnet size was $50 \times 50 \times 12 \mathrm{~mm}$. All configurations were tested with the same air gap of $25 \mathrm{~mm}$ and back plate (yoke) dimension of $375 \times 50 \times 3 \mathrm{~mm}$ except the fifth configuration where the yoke thickness was $15 \mathrm{~mm}$ instead of $3 \mathrm{~mm}$. Finally, an adhesion system was created which gave the maximum adhesion force of $39.4 \mathrm{~kg}$ with three yokes positioned at a distance $30 \mathrm{~mm}$ from each other and an overall adhesion force of $92 \mathrm{~kg}$ was obtained. Another novel magnetic adhesion mechanism has been reported for a wallclimbing robot that operates on reinforced concrete surfaces where the design parameters have been investigated by Finite Element Analysis [14].

The aim of the work reported in this paper is to investigate the effect of different parameters affecting the magnetic adhesion force, namely, the distance between magnets, air gap and yoke thickness. The Response Surface Methodology (RSM) is selected to design the experiments and to study the interaction effect of these parameters on the response. Using the experimental results, a quadratic regression equation is developed representing an empirical relationship between the response variable i.e. magnetic adhesion force and the independent variables. Numerical optimisation is conducted to predict the optimum variable conditions for maximum adhesion force. Validating experiments are carried out at different conditions to check the adequacy of the predicted quadratic model. Moreover, statistical validation is applied using ANOVA.

\section{MATERIALS AND MethodS}

\section{A. Experimental Setup}

Three neodymium grade N35 magnets with dimensions of $50 \times 50 \times 12.5 \mathrm{~mm}$ were attached with different steel backing plates called a yoke with dimensions $250 \times 50 \mathrm{~mm}$ and three different thicknesses. The three magnets were attached to the yoke with a specific configuration, where same polarity magnets were attached at the corners and one different polarity magnet in the middle. A test rig was designed, implemented and calibrated for measuring the magnetic adhesion force as shown in Fig. 1. The test rig was placed on a ferrous metal surface. The magnets attached to the yoke were placed on the internal frame of the test rig. Subsequently, the magnets attract the metal surface leading to an external force applied to the load cells and the adhesion force is shown in kilograms.

\section{B. Experimental Design}

Response Surface Methodology (RSM) is an emphatic model which is utilized for development of a mathematical model representing the response variable as function of studied process parameters. It is a combination of both statistical and mathematical approaches which has been introduced for modelling, modifying and optimising various processes [15].

RSM was used to set up a mathematical relationship between the response (the magnetic adhesion force) and the factors influencing the adhesion force (air gap, the distance between magnets and yoke thickness). A set of experiments were conducted using Box Behnken Design (BBD) where each independent parameter is varied between three levels. The three levels are equally spaced and coded as $-1,0,1$ as shown in Table 1 .

\section{Statistical Analysis}

A general quadratic polynomial equation was used to represent the developed model:

$$
Y=b_{o}+\sum_{i=1}^{n} b_{i} x_{i}+\sum_{i=1}^{n} b_{i i} x_{i}^{2}+\sum_{i=1}^{j-1} \sum_{j=2}^{n} b_{i j} x_{i} x_{j}+\varepsilon
$$

where $\mathrm{Y}$ is the corresponding response, $b_{i}, b_{i i}$ and $b_{i j}$ represent the linear, interactive, and quadratic coefficients respectively. $b_{o}$ represents the constant coefficient and $\varepsilon$ is the residual experimental error and $x_{i}, x_{j}$ are coded values of the input parameters.

Investigation of the statistical significance was analysed using ANOVA by calculating the Fisher's F-test at $95 \%$ confidence level. Lack of fit analysis has been used to measure the failure of the developed model to fit the experimental data. Design Expert software has been used for the optimisation, regression analysis and graphical analysis. Statistical significance of the results has been presented by p-value where the result is significant when $\mathrm{p}<0.05$.

TABLE I. DESIGN VARIABLES CODES.

\begin{tabular}{|c|c|c|c|c|}
\hline \multicolumn{2}{|c|}{ Factors } & Code & \multicolumn{3}{c|}{ Levels } \\
\hline \multicolumn{2}{|c|}{} & -1 & 0 & +1 \\
\hline Air Gap & A & 18.5 & 21.5 & 24.5 \\
\hline Distance between magnets & B & 20 & 35 & 50 \\
\hline Yoke thickness & C & 6 & 11 & 16 \\
\hline
\end{tabular}




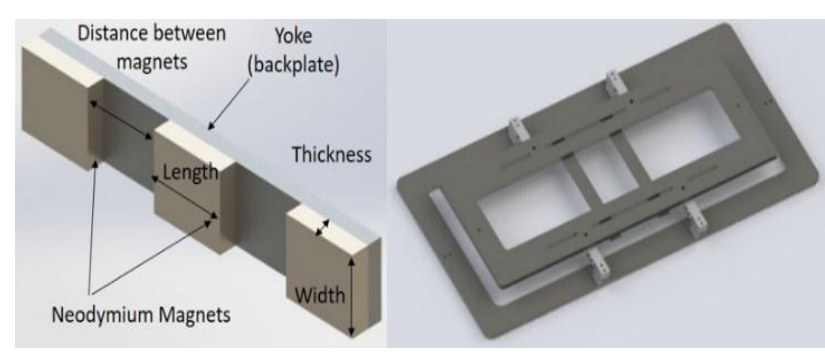

Figure 1. Test rig and magnet configuration.

\section{Finite Element Model}

A model has been created using COMSOL Multiphysics software as another validation method for the experimental results. The model is based on equation 2 which can be used by selecting magnetic field no current from $\mathrm{AC} / \mathrm{DC}$ module.

$$
-\nabla \cdot\left(\mu_{o} \nabla V_{m}-\mu_{o} M_{o}\right)=0
$$

where $V_{m}$ is the scalar magnetic potential, $\mu_{o}$ is free space permeability and $M_{o}$ is the magnetization.

The magnetic field is symmetric with reference to the $\mathrm{xz}$ and yz-plane where the magnetic field is tengential and antisymmetric with reference to the xy-plane where the magnetic field is perpendicular as shown in Fig. 2.

The model is surrounded by an adequately simulation volume where the dimensions are chosen large enough, with respect to the simulated volume, to minimise the impact of the extreme boundary condition presented at the edges on the region around the magnet.

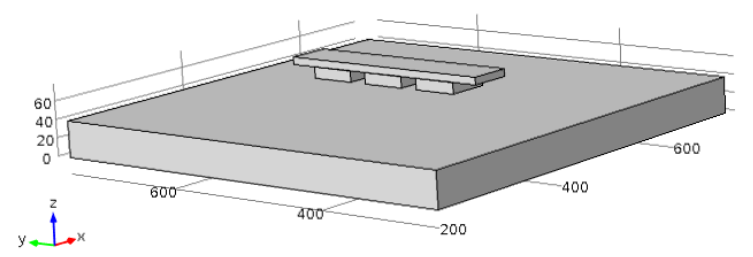

Figure 2. COMSOL Multiphysics model.

\section{RESULTS AND DISCUSSION}

\section{A. Model Validation And Adequacy Checking}

Using the experimental results, a quadratic regression equation has been developed representing an empirical relationship between the response variable and all the independent variables as shown in Equation 3.

$$
\begin{aligned}
Y=20.53-6.04 A & +0.78 B+2.82 C-0.096 A B-0.69 A C \\
& +0.5 B C+1.08 A^{2}-0.24 B^{2} \\
& -1.67 C^{2}
\end{aligned}
$$

where $Y$ is the adhesion force, $A, B$ and $C$ are air gap, distance between magnets and yoke thickness, respectively.
ANOVA has been applied to validate the developed model where it evaluated F-value of 278.79 and p-value of $<0.0001$, as shown in Table 2. Moreover, predicted results versus experimental actual results have been investigated as shown in Fig. 3. The similarity between predicted and actual results ensure the adequacy of the model for predicting the experimental data. These results conclude that the model successfully represents the experimental data.

ANOVA's assumptions including the normality of residuals and randomized observations have been analysed. Residuals are defined as the difference between the actual and predicted results. As shown in Fig. 4, normality of residuals has been investigated where the results are approaching a straight line which indicates the validity of the normality assumption of residuals. Secondly, randomisation of observations has been examined. Accordingly, a graphical plot between predicted observations and residuals is presented in Fig. 5. Randomised results have been observed where there is no trend for the results.

To validate the model experimentally, selected conditions have been tested which shows high agreement with the predicted values of the model. The average relative errors between the experimental and predicted values for the tested conditions is $0.95 \%$. The similarity between the predicted and actual value ensure the adequacy of the predicted model.

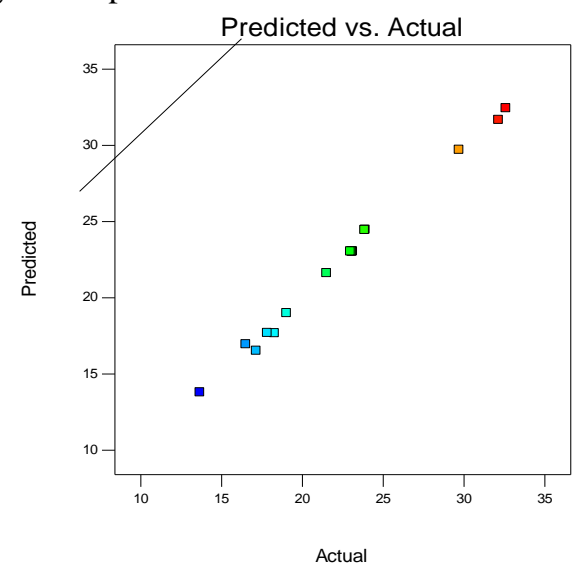

Figure 3. Predicted values developed by the model versus actual experimental data.

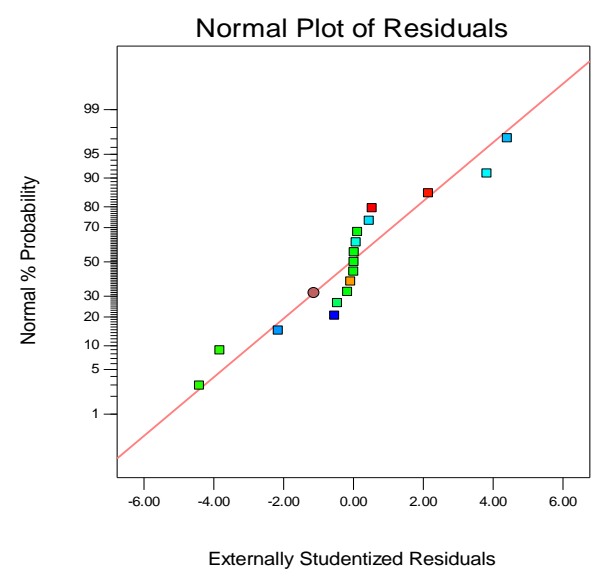

Figure 4. Normality of residuals. 


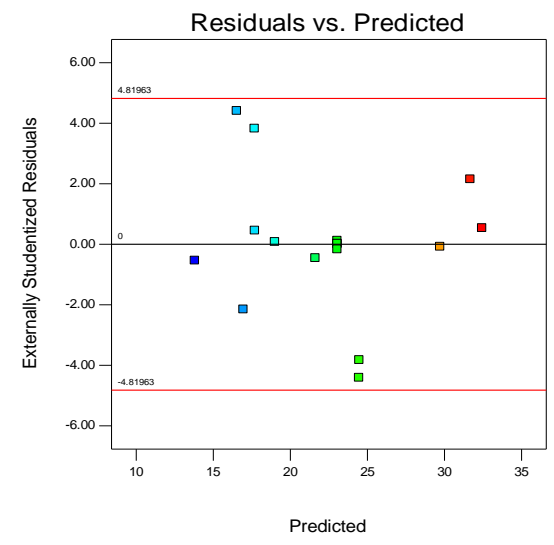

Figure 5. Predicted observations and residuals.

\section{B. Effect of Process Variables}

The 3D-surface and contour plots of the adhesion force versus interaction of two independent variables are shown in Fig. 6 to Fig. 9. In each plot, the remaining independent variable is kept constant at its centre point.

\section{1) Effect of air gap}

Based on the ANOVA results shown in Table 2, the air gap parameter shows a highly significant effect on the process response with p-value $<0.0001$ and F-value 1923.94. Fig. 6 and Fig. 7 illustrate the effect of air gap and distance between magnets while keeping the thickness of the yoke at the centre point $11 \mathrm{~mm}$, versus magnetic adhesion force where increasing the air gap decreases the adhesion force.

\section{2) Effect of distance between magnets}

It is clearly shown in Fig. 6 and Fig. 7 that increasing the distance between magnets increases the adhesion force while keeping the air gap fixed at $21.5 \mathrm{~mm}$. The distance between magnets shows the effect on the response with a p-value of 0.0004 and F-value of 39.65 using ANOVA as illustrated in Table 2.

\section{3) Effect of yoke thickness}

Yoke thickness to which magnets are attached has a considerable effect on the adhesion force as illustrated in Fig. 8 and Fig. 9. ANOVA results in Table 2 show the highly significant effect on the response variable where it has concluded the p-value and F-value of 0.0001 and 418.55, respectively.

\section{4) Optimisation of process variables}

An optimisation process of the independent parameters has been performed to conclude the maximum adhesion force at the minimal affecting variables.

TABLE II. ANALYSIS OF VARIANCE (ANOVA) FOR RESPONSE SURFACE DEVELOPED MODEL.

\begin{tabular}{|c|c|c|c|c|c|}
\hline Source & $\begin{array}{c}\text { Sum of } \\
\text { Squares }\end{array}$ & Df & $\begin{array}{c}\text { Mean } \\
\text { Square }\end{array}$ & F Value & p-value \\
\hline Model & 380.13 & 9 & 42.24 & 278.79 & $<0.0001$ \\
\hline A & 291.48 & 1 & 291.48 & 1923.94 & $<0.0001$ \\
\hline B & 6.01 & 1 & 6.01 & 39.65 & 0.0004 \\
\hline C & 63.41 & 1 & 63.41 & 418.55 & 0.0001 \\
\hline
\end{tabular}

Specific targets have been inserted into the software to guide the optimisation process. The response variable i.e. adhesion force has been set to a maximum. The yoke thickness has been targeted to be minimised to reduce the weight of the climbing robot. Air gap variable has been set to be minimum as it has the most significant effect on the adhesion force and to avoid the robot flipping over the wall. Finally, the distance between magnets has been minimised with lower importance as it has a relationship with the length of the yoke. The maximum adhesion force obtained from the optimisation process according to the constraints ststed above is $240.3 \mathrm{~N}$ at an air gap of 18.5 $\mathrm{mm}$, the distance between magnets $20 \mathrm{~mm}$ and yoke thickness of $8.3 \mathrm{~mm}$.

\section{Simulation of Magnetic AdHesion Force USING COMSOL MULTIPHYSICS}

Two simulations were investigated using COMSOL Multiphysics to study the parameters affecting the magnetic adhesion force and to validate optimum conditions obtained from the design of expert software. The results obtained in COMSOL Multiphysics showed the same trend with respect to the results extracted from Design Expert shown in Table 3.

More towards validating the quadratic regression model, the magnetic adhesion force has been simulated using COMSOL Multiphysics while varying the air gap distance. Three neodymium magnets are attached to a cast iron back plate (yoke) by two magnets on each corner with the same polarity and the middle one with reversed polarity. Dimensions of the magnet used are length $50 \mathrm{~mm}$, width $50 \mathrm{~mm}$, thickness $10 \mathrm{~mm}$, yoke thickness $20 \mathrm{~mm}$, length $260 \mathrm{~mm}$ and width $50 \mathrm{~mm}$. The distance between each two magnets are $55 \mathrm{~mm}$. The results show that as the air gap increases the magnetic adhesion force decreases exponentially as shown in Fig. 10 where the air gap is varying from zero to $20 \mathrm{~mm}$. The magnetic adhesion force without air gap was about 5300 $\mathrm{N}$ and at $20 \mathrm{~mm}$ air gap reaches to about $230 \mathrm{~N}$.

TABLE III. COMPARISON BETWEEN COMSOL MULTIPHYSICS AND DESIGN EXPERT

\begin{tabular}{|c|c|c|c|c|}
\hline \multicolumn{3}{|c|}{ Factors } & \multicolumn{2}{c|}{ Adhesion Force } \\
\hline Air Gap & $\begin{array}{c}\text { Distance bet. } \\
\text { magnets }\end{array}$ & $\begin{array}{c}\text { Yoke } \\
\text { thickness }\end{array}$ & COMSOL & $\begin{array}{c}\text { Design } \\
\text { expert }\end{array}$ \\
\hline $18.5 \mathrm{~mm}$ & $20 \mathrm{~mm}$ & $8.3 \mathrm{~mm}$ & $244.2 \mathrm{~N}$ & $240.3 \mathrm{~N}$ \\
\hline $22.5 \mathrm{~mm}$ & $30 \mathrm{~mm}$ & $9.3 \mathrm{~mm}$ & $173.6 \mathrm{~N}$ & $169.7 \mathrm{~N}$ \\
\hline
\end{tabular}

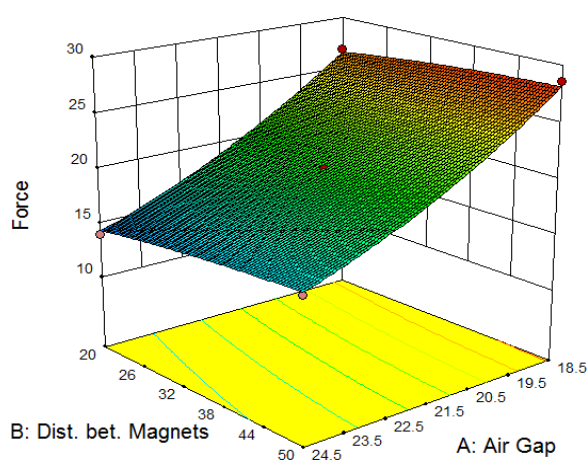

Figure 6. Surface plot for air gap and distance between magnets versus magnetic adhesion force. 


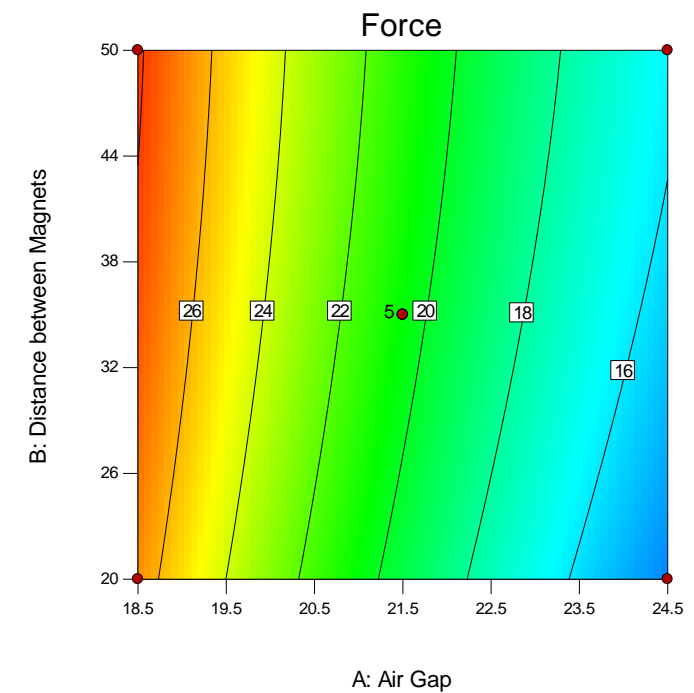

Figure 7. Contour graph for air gap and distance between magnets versus magnetic adhesion force.

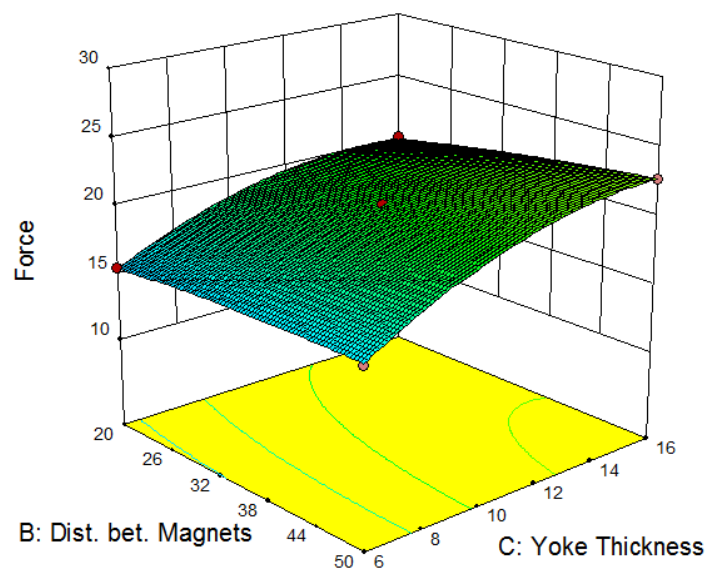

Figure 8. Surface plot and contour graph for yoke thickness and distance between magnets versus magnetic adhesion force.

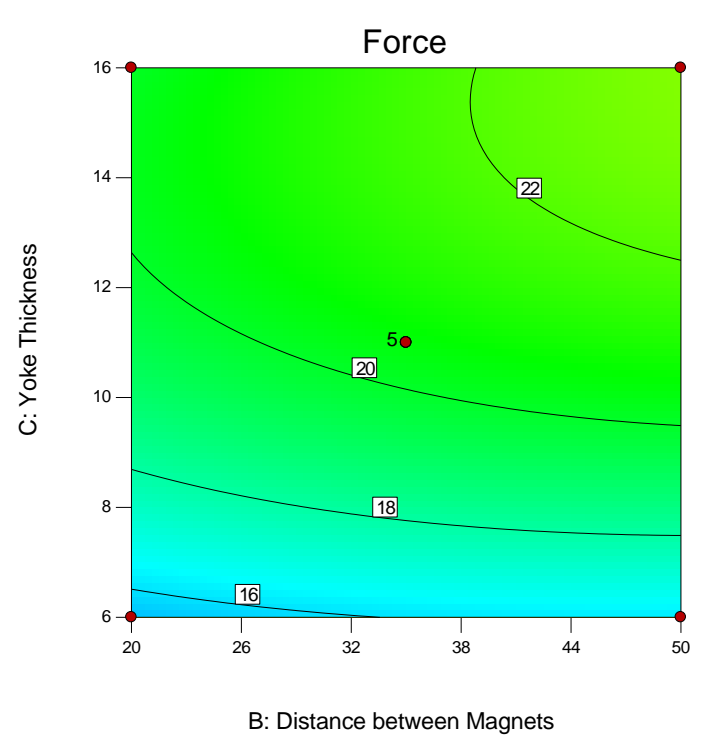

Figure 9. Contour graph for yoke thickness and distance between magnets versus magnetic adhesion force.

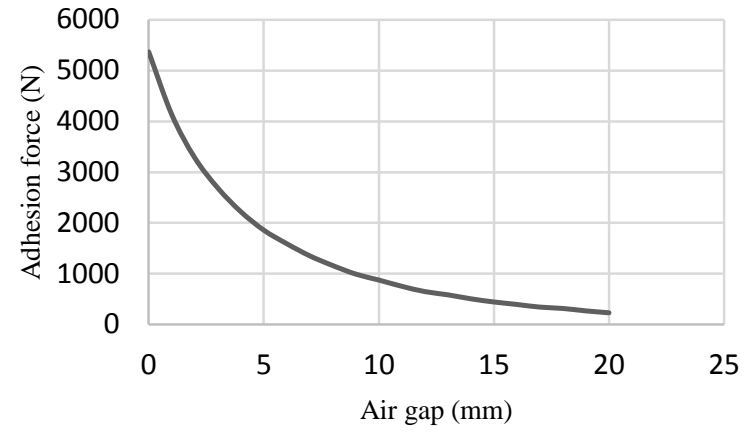

Figure 10. Varying air gap.

\section{THE DESIGN OF THE WALL CLIMBING ROBOT}

A design of the wall climbing robot was implemented for the robot. The robot was designed with wheels as a locomotion technique to provide the robot with continuous motion and permanent magnets for adhesion to the wall. The robot consists of seven parts. These are the chassis, wheels, motors, motor coupler, motor bracket, yoke and magnets. Fig. 11 illustrates the drawing of the wall climbing robot.

\section{A. Robot Chassis}

The robot chassis is constructed from aluminium plate with dimension $316 \times 250 \mathrm{~mm}$ and thickness $3 \mathrm{~mm}$. the length of the chassis dimension has been chosen according to the length of the motors in addition to a proper distance for motor connections. While the width is chosen to keep the motors away from the magnetic flux region in order not to affect the operation of the motor. The material of the robot is aluminium to have a light weight structure while holding the magnets with the yoke in the middle.
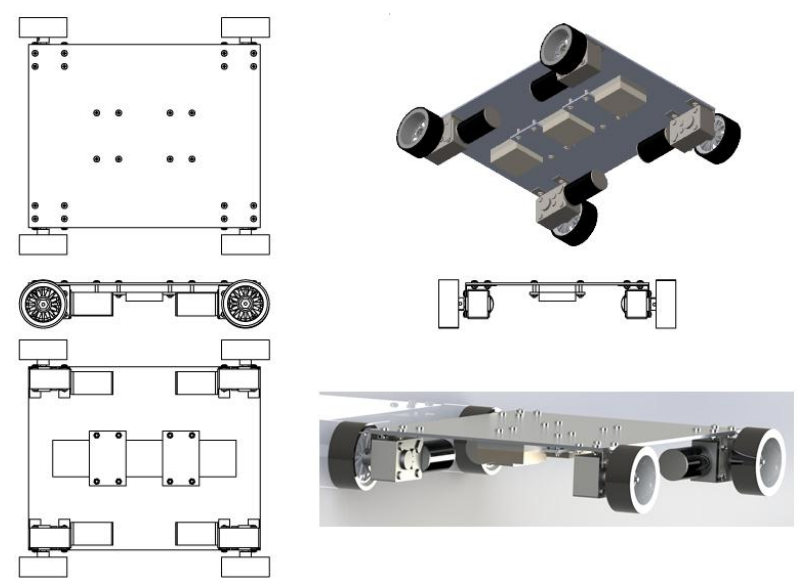

Figure 11. Wall climbing robot.

\section{B. Motors}

The robot is equipped with four DC motors with worm gearboxes to generate high torque to overcome the adhesion force during the robot motion. The motors are fixed in line with the corner of the chassis to give the robot the ability to transfer from one plane to another. 
The robot is equipped with four rubber wheels for greater traction.

\section{Motor Bracket}

Each drive motor is attached to the chassis with two Lshape steel brackets.

\section{Yoke and Magnets}

The yoke and magnets are attached to the robot chassis in the middle with eight machine screws fastened to the aluminium plate placed in the distance between magnets. The back plate (yoke) is iron with dimension $50 \times 250 \times 11$ $\mathrm{mm}$ as shown in Fig. 1. Three neodymium N35 magnets are attached to the yoke. The dimension of each magnet is $50 \times 50 \times 12.5 \mathrm{~mm}$ and the distance between magnets is 50 $\mathrm{mm}$.

\section{E. Motor Coupler}

To transfer the power of the motor to the wheels, a motor coupler is designed to connect the shaft of the motor to the wheel as shown in Fig. 12. The coupler has a hexagonal end to fit inside the wheel to avoid wheel slippage during climbing due to the strong adhesion force.

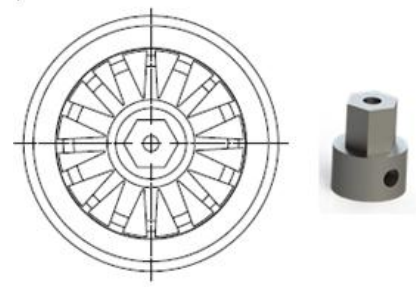

Figure 12. Wheel and motor coupler.

\section{F. Robot Implementation}

The robot is implemented according to the model described previously and tested on a steel surface as shown in Fig. 13 to check the capability of the magnetic adhesion force to attach the robot to a steel plate.

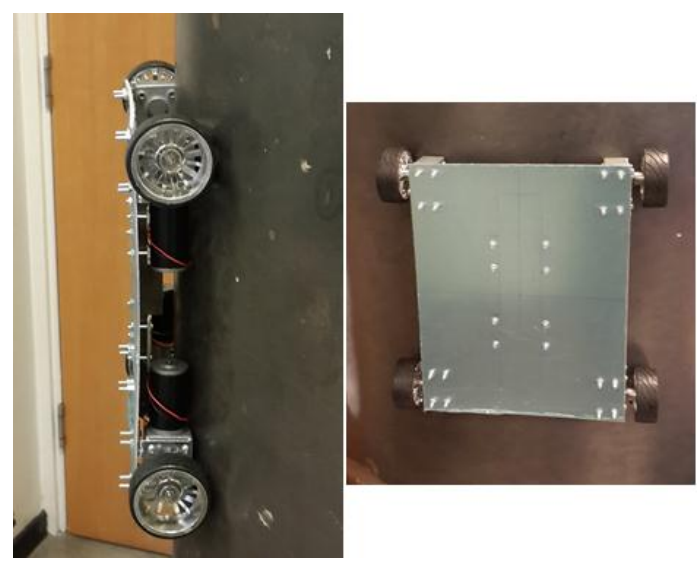

Figure 13. Robot.

\section{CONCLUSION}

RSM has been used to design experiments and investigate the effect of independent variables on the process response. A quadratic polynomial model has been obtained for the response variable function in all independent variables. Optimum conditions have been concluded from the quadratic polynomial model for adhesion force of $240.3 \mathrm{~N}$ at $20 \mathrm{~mm}$ distance between magnets, $18.5 \mathrm{~mm}$ air gap and $8.3 \mathrm{~mm}$ for yoke thickness. Experimental and statistical validation has been applied for the predicted model resulting in high agreement between response values. The average relative errors between the tested experimental values and predicted values using the quadratic polynomial model is $0.95 \%$. To examine the robustness of this module a couple of points have been simulated using finite element simulator where an acceptable agreement has been observed. Finally, a prototype climbing robot was implemented by employing the extracted design parameters from the quadratic polynomial model.

The work performed in this paper could be extended to a wider range of adhesion forces using different predicted levels of the independent variables.

\section{REFERENCES}

[1] A. Brusell, G. Andrikopoulos, and G. Nikolakopoulos, "Novel considerations on the negative pressure adhesion of electric ducted fans: An experimental study," in Proc. 2017 25th Mediterranean Conference on Control and Automation (MED), 2017, pp. 14041409.

[2] Y. Liu, S. Sun, X. Wu, and T. Mei, "A wheeled wall-climbing robot with bio-inspired spine mechanisms," Journal of Bionic Engineering, vol. 12, pp. 17-28, 2015.

[3] D. Ruffatto, A. Parness, and M. Spenko, "Improving controllable adhesion on both rough and smooth surfaces with a hybrid electrostatic/gecko-like adhesive," Journal of The Royal Society Interface, vol. 11, p. 20131089, 2014.

[4] R. Sahay, H. Y. Low, A. Baji, S. Foong, and K. L. Wood, "A state-of-the-art review and analysis on the design of dry adhesion materials for applications such as climbing micro-robots," Rsc Advances, vol. 5, pp. 50821-50832, 2015.

[5] R. V. Espinoza, A. S. de Oliveira, L. Valéria, R. de Arruda, and F. N. Junior, "Navigation's stabilization system of a magnetic adherence-based climbing robot," Journal of Intelligent \& Robotic Systems, vol. 78, p. 65, 2015.

[6] A. Brusell, G. Andrikopoulos, and G. Nikolakopoulos, "A survey on pneumatic wall-climbing robots for inspection," in Proc. 2016 24th Mediterranean Conference on Control and Automation (MED), , 2016, pp. 220-225.

[7] S. Kawasaki and K. Kikuchi, "Development of a small legged wall climbing robot with passive suction cups," in Proc. the 3rd International Conference on Design Engineering and ScienceICDES, 2014, pp. 112-16.

[8] D. Ge, T. Matsuno, Y. Sun, C. Ren, Y. Tang, and S. Ma, "Quantitative study on the attachment and detachment of a passive suction cup," Vacuum, vol. 116, pp. 13-20, 2015.

[9] G. Lee, H. Kim, K. Seo, J. Kim, and H. S. Kim, "MultiTrack: A multi-linked track robot with suction adhesion for climbing and transition," Robotics and Autonomous Systems, vol. 72, pp. 207216, 2015.

[10] D. Cui, D. Chen, H. Dong, L. Zhang, F. Qi, Y. Lei, et al., "Design and analysis of climbing robot based on construction surface inspection," in Proc. Control and Decision Conference (CCDC), 2016 Chinese, 2016, pp. 5331-5336.

[11] W. Bei, X. Fengyu, and Y. Zhong, "Grasping mechanism and prototype experiment of bionic sharp hook on rough surface," in Proc. 2016 23rd International Conference on Mechatronics and Machine Vision in Practice (M2VIP), 2016, pp. 1-6.

[12] J. Mao, L. Qin, Y. Wang, J. Liu, and L. Xue, "Modeling and simulation of electrostatic attraction force for climbing robots on the conductive wall material," in 2014 IEEE International Conference on Proc. Mechatronics and Automation (ICMA), 2014, pp. 987-992. 
[13] T. P. Sattar, P. Hilton, and M. Howlader, "Deployment of laser cutting head with wall climbing robot for nuclear decommissioning," 2016.

[14] M. D. Omar and T. Pervez, Finite Element Analysis based Optimization of Magnetic Adhesion Module for Concrete Wall Climbing Robot vol. 6, 2015.

[15] O. Aboelazayem, M. Gadalla, and B. Saha, "Biodiesel production from waste cooking oil via supercritical methanol: Optimisation and reactor simulation," Renewable Energy, 2017.

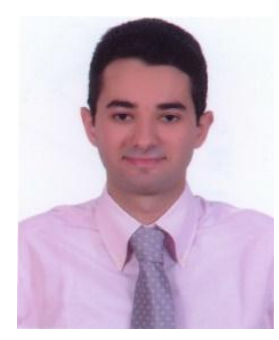

Anwar M. Sahbel Was graduated with B.Sc. in Mechanical Engineering Mechatronics branch, Higher Technological Institute, Tenth of Ramadan City, Egypt 2009. Master of science in Mechatronics Engineering, Ain Shams University, Cairo, Egypt 2014. Currently, enrolled as $\mathrm{PhD}$ student in London South Bank University since 2015.

He was working as a Teaching Assistant in Mechanical Engineering Department Mechatronics branch, Higher Technological Institute Tenth of Ramadan City, Egypt from September 2009 to January 2011. Currently, He is working as Assistant Lecturer in The British University in Egypt since February 2011. During his master thesis he succeeded to publish conference proceeding paper entitled "Experimental Performance Characterization of Photovoltaic Modules Using DAQ" TERRAGREEN13 international conference, ELSEVER, Lebanon, Feb. 2013.

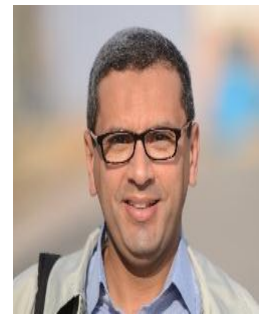

Ayman S. Abbas, Assoc. Prof was graduated with B.Sc. (Honours) in Design and Production Engineering in 1992 from Shoubra Faculty of Engineering, Zagazig University. He obtained his Ph.D. in 1998 from the University of Strathclyde, UK, in Computer Aided Design. Upon his return from the UK, he joined one of the private higher education institutions in Egypt, where he helped develop the curriculum of the Mechatronics Engineering department.
Dr. Abbas worked in several research projects and taught various design and automation courses at his last post.

Dr Abbas joined the BUE in 2006 to co-establish the Mechanical Engineering Programme. Since then, he was involved in the establishment of an up-to-date curriculum and its continuous review and development. Together with the Head of Department, their efforts culminated in the successful validation of the programme initially by Loughborough University and subsequently by London South Bank University, according to the QAA regulations which was achieved in August 2007 and sustained ever since. He acted as the departmental Teaching and Learning Coordinator since validation. From September 2013 to October 2017, Dr Abbas was appointed Programme Director for Mechanical Engineering. Dr Abbas has extensive experience in the areas of design education, kinematics and dynamics of machines and robotics and automation studies. He has several published journal and conference papers in these fields. Dr Abbas also acted as an initiator for Robot Contests in Egypt and has supervised teams successfully on the local, regional and international levels.

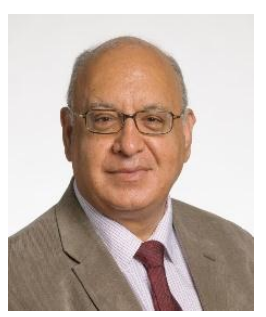

Tariq P. Sattar, Professor BSc (Bio), BSc (EEE), PhD (Control), MIET, FBINDT

$\mathrm{He}$ is currently the Head of the Robotics Centre, London South Bank University, School of Engineering, London, United Kingdom.

He has been at the university from January 1986 to May 2015 and has served in many positions including as the head of the Department of Electrical, Computer and Communications Engineering.

From July 2015 to present, he is also the TWI Chair and Director of the London South Bank Innovation Centre for the Automation of NDT, which is based in TWI Ltd, Cambridge, United Kingdom where he leads a large team of research fellows and postgraduate researchers. 